Syntax Idea: p-ISSN: 2684-6853 e-ISSN: 2684-883X

Vol. 3, No. 3, Maret 2021

\title{
ANALISIS KEPUTUSAN MEMBELI BERBASIS BRAND AWARENESS SEBAGAI IMPAK GOOGLE ADS DAN FACEBOOK ADS (KAJIAN PELANGGAN LAZADA)
}

\section{Bertinus Sijabat}

Universitas Sarjana wiyata Tamansiswa Yogyakarta, Indonesia

Email: bensjabat@gmail.com

\section{Abstract}

This research aims to test Brand Awareness Based Buying Decision Analysis as an Impact on Google Ads and Facebook Ads. The study was conducted on 97 respondents who are Lazada customers. The results of this study showed: 1). Google Ads variable (X1) with Brand Awareness (Y1) proved to have an effect and significant effect on Brand Awareness, with a parameter coefficient of 0.5081 ( $P$ Value <0.05) of 0.0000. This indicates that google ads variables have a significant effect on Brand Awareness (Y1) variables. 2). The Facebook Ads variable (X2) with Brand Awareness (Y1) proved to be influential and significant to Brand Awareness, with a parameter coefficient of 0.3447 and a $P$ Value $<$ of 0.05 of 0.0000. This indicates that the Facebook Ads variable affects the Brand Awareness (Y1) variable. 3). The Google Ads variable (X1) with the Purchase Decision (Y2) proved significant effect on the Buying Decision with a parameter coefficient of 0.2385 and $P$ Value < of 0.05 of 0.0009. This suggests that Google Ads variables have an effect on buying decision variables (Y2). 4). The Facebook Ads variable (X2) with the purchase decision (Y2) proved to have an effect and significant effect on the buying decision i.e. with a parameter coefficient of 0.2761 and $P$ Value $<$ of 0.05 of 0.0020. This indicates that the Facebook Ads variable affects the buy decision variable (Y2). 5). Variable Brand Awareness (Y1) with the decision to buy (Y2) proved influential and significant to the Buying Decision with a parameter coefficient of 0.4497 and $P$ Value $<0.05$ of 0.0000. This indicates that the Brand Awareness variable is proven to have an effect on the Buying Decision (Y2) variable.

Keywords: google ads; facebook ads; brand awareness; buying decision

\section{Abstrak}

Penelitian ini bertujuan untuk menguji analisis keputusan pembelian berbasis Brand Awareness sebagai dampak pada Google Ads dan iklan Facebook. Penelitian dilakukan terhadap 97 responden yang merupakan pelanggan Lazada. Hasil penelitian ini menunjukkan: 1). Variabel Google Ads (X1) dengan brand awareness (Y1) terbukti memiliki efek dan efek yang signifikan terhadap brand awareness, dengan parameter koefisien 0,5081 ( $\mathrm{P}$ Value <0,05) sebesar 0,0000. Hal ini menunjukkan bahwa variabel Google Ads memiliki efek signifikan pada variabel brand awareness (Y1). 2). Variabel iklan Facebook (X2) dengan brand awareness (Y1) terbukti berpengaruh dan signifikan terhadap brand awareness dengan parameter koefisien 0,3447 dan $\mathrm{P}$ Value $<0,05$ dari 0,0000. Ini menunjukkan 
bahwa variabel Iklan Facebook mempengaruhi variabel brand awareness (Y1). 3). Variabel Google Ads (X1) dengan keputusan pembelian (Y2) terbukti memiliki efek signifikan pada keputusan pembelian dengan parameter koefisien 0,2385 dan nilai $\mathrm{P}<0,05$ sebesar 0,0009. Ini menunjukkan bahwa variabel Google Ads mempengaruhi variabel keputusan pembelian (Y2). 4). Variabel iklan Facebook (X2) dengan keputusan pembelian (Y2) terbukti memiliki efek dan efek yang signifikan pada keputusan pembelian yaitu dengan parameter koefisien 0,2761 dan $\mathrm{P}$ Value $<0,05$ dari 0,0020. Ini menunjukkan bahwa variabel iklan Facebook mempengaruhi variabel keputusan pembelian (Y2). 5). Variable brand awareness (Y1) dengan keputusan untuk membeli (Y2) terbukti berpengaruh dan signifikan terhadap keputusan pembelian dengan parameter koefisien 0,4497 dan nilai $\mathrm{P}<$ 0,05 dari 0,0000. Ini menunjukkan bahwa variabel Brand Awareness terbukti memiliki efek pada variabel keputusan pembelian (Y2).

Kata kunci: Google Ads; iklan Facebook; kesadaran merek; keputusan membeli

Coresponden Author

Email: bensjabat@gmail.com Artikel dengan akses terbuka dibawah lisensi

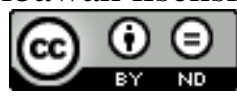

\section{Pendahuluan}

Menurut The World Economic Forum dua karakteristik utama evolusi adalah difusi teknologi dan disrupsi marketplace. Pertama, revolusi industri 4.0 ditandai dengan revolusi yang mengaburkan garis antara fisik, digital, dan bidang biologis termasuk konteks bisnis. Kedua, adopsi, penggunaan, dan difusi teknologi zaman baru oleh bisnis berkontribusi untuk meningkatkan interaksi perusahaan-pelanggan (Gupta, Leszkiewicz, Kumar, Bijmolt, \& Potapov, 2020).

Industri 4.0 mengubah model bisnis perusahaan manufaktur. Teknologi ini dapat mendukung fleksibilitas, efisiensi, dan produktivitas melalui berbagai hadirnya teknologi komunikasi, informasi dan inteligent (Ibarra, Ganzarain, \& Igartua, 2018). Serangkaian manfaat, industri 4.0 antara lain: dapat memberi perusahaan manufaktur model bisnis yang menguntungkan, efisiensi yang lebih tinggi, kualitas, dan kondisi tempat kerja yang lebih baik (Bai, Dallasega, Orzes, \& Sarkis, 2020).

Industri 4.0 mengubah model bisnis perusahaan manufaktur. Teknologi ini dapat mendukung fleksibilitas, efisiensi dan produktivitas melalui berbagai hadirnya teknologi komunikasi, informasi dan intelegent (Ibarra Zuluaga, Ganzarain Epelde, \& Igartua López, 2018). Serangkaian manfaat, industri 4.0 antara lain: dapat memberi perusahaan manufaktur model bisnis yang menguntungkan, efisiensi yang lebih tinggi, kualitas dan kondisi tempat kerja yang lebih baik (Bai et al., 2020).

Akibat kemajuan teknologi, jumlah data digital yang luar biasa dihasilkan setiap hari. Para pengguna internet meninggalkan jejak digital, sehingga beragam perilaku online dapat dilacak dan dikumpulkan untuk mempelajari informasi rinci tentang setiap pengguna. Kekayaan data online menjanjikan banyak sekali keuntungan bagi para 
pelanggan, dalam bentuk layanan yang dipersonalisasi, konten individual, serta pesan dan penawaran yang relevan (Martin \& Murphy, 2017).

Seiring perkembangan teknologi, konsumen semakin memperoleh keuntungan akses ke platform media digital dan media sosial sebagai sarana mengungkapkan pendapat dan berinteraksi dengan perusahaan. Banyak perusahaan mengalihkan sumber daya promosi dari media tradisional dan mulai menggunakan platform digital untuk berinteraksi langsung pelanggan (Paruthi \& Kaur, 2017).

Teknologi telah berkembang secara eksponensial dalam beberapa dekade terakhir dan diintegrasikan pada berbagai tingkatan dalam operasi bisnis dan gaya hidup seharihari konsumen (Farah \& Ramadan, 2017). Perusahaan yang berhasil dalam mengintegrasikan solusi teknologi canggih dalam melayani konsumen akhir biasanya menerima umpan balik positif dibandingkan perusahaan lain yang gagal melakukannya (Ramadan, Farah, \& Kassab, 2019).

Perubahan perilaku konsumen Indonesia terlihat dari peningkatan penetrasi pengguna internet Indonesia dari tahun ke tahun. Hasil survei Asosiasi Penyelenggara Jasa Internet Indonesia mengungkapkan adanya pergerakan akses internet di Indonesia. Pada tahun 2016, jumlah penetrasi pengguna internet di Indonesia adalah sebesar 132,7 juta orang (Widiartanto, 2016). Pada tahun 2017 terjadi peningkatan sehingga jumlah pengguna internet di Indonesia adalah sebesar 143,25 juta orang. Tahun 2018, jumlah pengguna internet di Indonesia sudah mencapai 171,17 juta orang. Data ini menyatakan bahwa tingkat penetrasi internet pada tahun 2018 sudah mencapai 64,8\% dari semua penduduk yang berjumlah 264,16 juta jiwa (Franedya, 2019).

Hasil riset We Are Social dan Hootsuite pada tahun 2018 mengungkapkan setiap hari penduduk Indonesia mengakses internet melalui perangkat apa pun selama 7 jam, 59 menit. Waktu untuk mengakses media sosial melalui perangkat apa pun adalah selama 3 jam, 26 menit. Waktu untuk menonton TV (broadcast, streaming dan tayangan video) adalah 3 jam 4 menit. Waktu untuk menonton streaming musik adalah 1 jam, 22 menit, waktu untuk bermain game adalah 1 Jam 23 menit (Kemp, 2019).

Hasil survei We Are Social menyatakan bahwa selama tahun 2019, Indonesia menduduki peringkat ketiga, di bawah India dan China dengan pertumbuhan penetrasi internet di dunia. Kata kunci penelusuran tertinggi di dunia melalui Google Search adalah Facebook, Youtube, Whatsapp, You, dan Weather (We Are Social \& Hootsuite, 2020).

Website yang paling banyak dikunjungi oleh pengakses internet di Indonesia adalah Google.com. Youtube.com, Facebook.com, Tribunnews.com dan Detik.com. Sementara, secara internasional, portal yang paling banyak diakses di seluruh dunia adalah Google.com, Youtube.com, Facebook.com, Baidu.com, Wikipedia.org (We Are Social \& Hootsuite, 2020).

We Are Social dan Hootsuite juga merilis bahwa selama tahun 2019, jumlah orang yang melakukan belaja barang konsumsi adalah sebesar 168,3 juta orang. Transaksi ini menghasilkan belanja senilai 18,76 milyar dollar Amerika Serikat (We Are Social \& Hootsuite, 2020). 
Pada tahun 2017, posisi pemimpin pasar marketplace di Indonesia adalah Lazada, Tokopedia, Bukalapak, Blibli dan Shoope. Hasil riset iPrice ini diperoleh berdasarkan popularitas marketplace dari berdasarkan volume penelusuran berbasis Google Trend (Medcom.id, 2017). Pada tahun 2018, laporan iPrice menunjukkan adanya pergeseran posisi e-commerce di Indonesia. Pada tahun 2018, Tokopedia menjadi e-commerce peringkat pertama, disusul Lazada, Shopee, dan Bukalapak. Walau demikian, Lazada masih menjadi pemimpin e-commerce di Asia Tenggara dengan market 25\% dibandingkan dengan e-commerce lainnya (iPrice, 2018).

Menurut laporan iPrice tahun 2019, Lazada menjadi pemimpin pasar e-commerce di Asia Tenggara berdasarkan jumlah pengguna aktif bulanan terbanyak di 4 dari 6 negara. Namun, untuk pasar Indonesia, jumlah kunjungan per bulan (Montly Web Visits) Lazada hanya berada di peringkat empat di bawah Tokopedia, Shopee, dan Bukalapak (Liputan6.com, 2019).

Menurut riset MarkPlus.Inc yang dirilis 17 September 2020, pada kuartal III tahun 2020, Shopee berhasil menjadi e-commerce peringkat tertinggi di Indonesia sebagai brand yang digunakan dalam tiga bulan terakhir. Tingkat proporsi penggunaan Shopee 90\%, Tokopedia 58 persen, Lazada 35 persen, Bukalapak 22 persen, Blibli 14 persen, dan JD.id 13 persen. Shopee juga menjadi e-commerce dengan top of mind atau paling diingat konsumen dengan 71 persen, Tokopedia 15 persen, Lazada 8 persen, Bukalapak 2 persen, serta JD.id dan Blibli 1 persen (Bisnis.com, 2020).

Tingkat persaingan e-commerce sangat ketat. Data laporan iPrice 2020 menunjukkan pergeseran pemimpin pasar e-commerce di Indonesia. Jika pada tahun 2019, peringkat tertinggi diraih oleh Tokopedia, ternyata pada tahun 2020 posisi tertinggi e-commerce diraih oleh Shopee. Pada kuartal II-2020, portal Shopee diakses oleh 93,44 juta orang pengunjung per bulan. Sementara, Tokopedia diakses oleh 86,103 juta orang per bulan. Bukalapak yang diakses oleh 35,288 juta orang per bulan. Lalu, Lazada diakses oleh 22,021 juta oranag dan Blibli diakses oleh 18,307 juta pelanggan setiap bulan (CNBC Indonesia, 2020).

Tren penurunan kunjungan ke Lazada terus terjadi dari tahun 2017 hingga tahun 2020. Penurunan selama 4 tahun berturut-turut tentu menjadi masalah yang harus diatasi oleh Lazada. Tingkat kunjungan dan tingkat pengguna aktif Lazada yang terus-menerus menurun dapat menggerus perusahaan secara signifikan. Kondisi ini tentu terjadi karena tingkat persaingan yang sangat ketat dengan e-commerce lainnya. Situasi ini tentu tidak kondusif, sehingga Lazada harus segera berbenah dengan berbagai strategi yang jitu, sehingga lebih mampu lagi bersaing dengan e-commerce lainnya.

Hasil penelitian (Shahid et al., 2017), (Za \& Tricahyadinata, 2017), ( Lee et al., 2018), (Tata et al., 2019), (Swamy et al., 2019), (Dreher et al., 2018), (Upadhyay et al., 2019), (Zia \& Rao, 2019), (Rybaczewska et al., 2020) menyatakan bahwa Google Ads mempengaruhi Brand Awareness.

Hasil penelitian (Dehghani \& Tumer, 2015), (E.B, 2016), (Pancaningrum \& Rahayu, 2017), (Tikno, 2017), (M.S et al., 2018), (Wiese et al., 2020), (S. Huang et al., 2020), (Chodick et al., 2020), (Chierici et al., 2019) menyatakan bahwa Facebook Ads 
berpengaruh terhadap peningkatan brand awareness. Sebaliknya, menurut hasil penelitian (Vries et al., 2017), (Sung et al., 2020), menyatakan bahwa Facebook Ads tidak efektif dalam meningkatkan brand awareness.

Hasil penelitian dari (Za \& Tricahyadinata, 2017), (Dreher et al., 2018), (Pamungkas \& Fanani, 2018), (Lee et al., 2018), (Tata et al., 2019), (Upadhyay et al., 2019), (Putra, 2019), (Zia \& Rao, 2019), (Rybaczewska et al., 2020) menyatakan bahwa Google Ads mempengaruhi keputusan membeli. Sebaliknya, hasil penelitian dari (Ursu, 2018), (Medina et al., 2020), (Zhang, 2020) menyatakan bahwa Google Ads tidak mempengaruhi keputusan membeli.

Hasil penelitian dari (Arie et al., 2015),(Cahyani \& Sutrasmawati, 2016), (Mulyono, 2016), (Timpal et al., 2016), (Kilei et al., 2016), (M. Asnawi et al., 2017) (Raharjo \& Prof. Dr. Hatane Semuel S.E., 2018), (Ramadayanti, 2019), (Zia \& Rao, 2019), (A et al., 2020),(Pranata \& Pramudana, 2018), (Kusuma \& Miartana, 2018) (Chierici et al., 2019) menyatakan bahwa brand awareness mempengaruhi keputusan membeli. Sebaliknya, hasil penelitian (Wasil, 2017) menyatakan bahwa brand awareness tidak berpengaruh secara signifikan terhadap keputusan membeli.

Hasil penelitian dari (Za \& Tricahyadinata, 2017), (Dreher et al., 2018), (Pamungkas \& Fanani, 2018), (Lee et al., 2018), (Tata et al., 2019), (Swamy et al., 2019), (Upadhyay et al., 2019), (Putra, 2019), (Zia \& Rao, 2019), (Rybaczewska et al., 2020) menyatakan bahwa Google Ads mempengaruhi keputusan membeli.

\section{Metode Penelitian}

\section{A. Populasi dan Jumlah Sampel}

Populasi pelanggan Lazada di Yogyakarta tidak diketahui jumlahnya secara persis. Dalam penelitian ini jumlah sampel adalah 97 orang pelanggan Lazada. Alat analisis yang digunakan adalah pengujian validitas, uji reliabilitas, analisis deskriptif, analisis infrensial dan pengujian hipotesis.

\section{B. Kerangka Pemikiran}

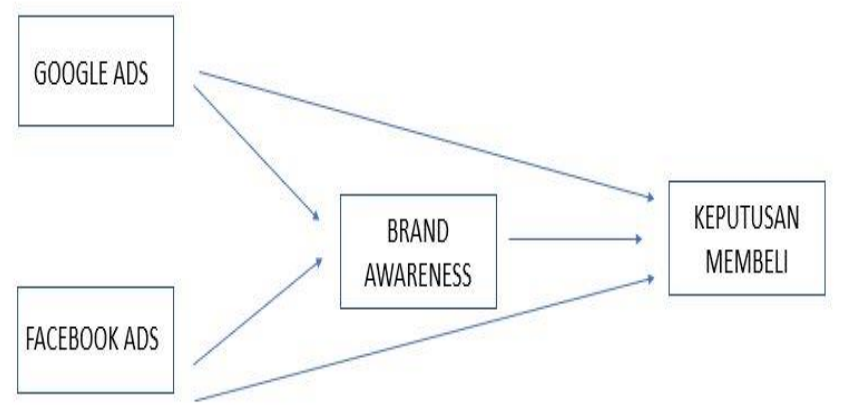

Gambar 1 Kerangka Pemikiran Penelitian 


\section{Defenisis Operasional}

Definisi operasional adalah konsep yang membantu pemecahan karakteristik dari objek yang abstrak menjadi elemen-elemen atau indikator-indikator yang dapat diobservasi (Gendro Wiyono, 2011).

\section{Google Ads (X)}

Google Ads merupakan periklanan online dari Google yang menggunakan sistem penawaran sehingga iklan yang dibuat oleh pengelola -commerce muncul di halaman penelusuran Google. Tampilan iklan akan muncul di bagian atas atau kanan hasil pencarian. Saat pengguna mengetik kata kunci atau frase di pencarian Google, Google akan menampilkan iklan terkait (Za \& Tricahyadinata, 2017). Google Ads menempatkan nama, gambar, dan peringkat produk di hasil penelusuran produk (Huang et al., 2020).

Pengiklan bisa menentukan penempatan iklan berdasarkan keyword (kata atau frasa kunci) tertentu, waktu, ataupun lokasi. (Gityandraputra, 2020). Indikator pengukuran variabel Google Ads menurut (Chris, 2019) adalah:
1. Click Through Rate (CTR)
2. Quality Score
3. Conversion Rate (CR)
4. Cost Per Conversion (CPC).
5. Search Impression Share

\section{Facebook Ads (X2)}

Facebook Ads (iklan Facebook) adalah stimulus yang dirancang untuk mendorong setiap konsumen untuk terlibat dengan merek atau produk. Efektivitas iklan biasanya diukur dari segi percakapan, rasio klik-tayang, tindakan perilaku menglik iklan, atau perilaku pembelian (Wiese et al., 2020). Facebook Ads memberikan kemudahan bagi para penggunanya untuk bisa mengiklankan sendiri bisnis sesuai dengan keinginan sang pemilik bisnis (Techfor, 2019) Indikator variabel Facebook Ads (Leanne, 2020) adalah:

\section{Boosted Posts}

2. Page like ads

3. Reach/Brand Awareness Ads.

4. Traffic Ads

5. Conversion ads

\section{Brand Awareness (Y1)}

Brand awareness (kesadaran merek) adalah kemampuan konsumen untuk yang menyebutkan merek secara spontan sebagai merek yang beroperasi di industri tertentu tanpa bantuan kesadaran (Vries et al., 2017). Brand awareness adalah komponen fundamental dari ekuitas merek, kesadaran merek mencerminkan arti penting merek di benak pelanggan (Sürücü, Öztürk, Okumus, \& Bilgihan, 2019). Semakin tinggi tingkat kesadaran merek suatu merek dalam benak konsumen maka semakin besar kemungkinan merek akan dibeli dan 
dipilih oleh konsumen (Sürücü et al., 2019). Indikator kesadaran merek (Gunawardane, 2015) adalah:

1. Recall Power. Dapat mengingat symbol atau logo produk dengan cepat.

2. Point of Difference. Dapat menyebutkan perbedaan antara merek.

3. Knowledge about the Brand. Dapat memahami merek dengan sangat baik.

4. Position of Choice Set. Memahami karakteristik merek melalui ciri khas merek

5. Recall of competitive Brands. Mengetahui dan mengenali merek pesaing.

\section{Keputusan pembelian (Y2)}

Keputusan pembelian didefinisikan sebagai sebuah pilihan dari dua atau lebih alternatif pilihan (Schiffman \& Wisenblit, 2015). Proses keputusan pembelian dipengaruhi secara signifikan oleh faktor aspek sumber daya manusia, citra perusahaan sebagai pemberi kerja, minat inti ritel, layanan pemasaran yang berkontribusi pada difrensiasi di antara pesaing di pasar (Rybaczewska et al., 2020). Indikator keputusan pembelian (Kotler \& Kevin, 2016) adalah:

1. Kemantapan pada sebuah produk.

2. Kebiasaan dalam membeli produk.

3. Memberikan rekomendasi pada orang lain.

4. Melakukan pembelian ulang.

\section{Hasil dan Pembahasan}

\section{A. Uji Validitas dan Reliabilitas}

Sebuah instrument dapat dikatakan valid apabila mampu mengungkap data variabel yang diteliti secara tepat (Arikunto, 2013). Instrumen yang sudah dipercaya, yang reliabel akan menghasilkan data yang dapat dipercaya. Reliabilitas menunjukan pada tingkat keterandalan sesuatu. Reliabel artinya dapat dipercaya, jadi dapat diandalkan (Arikunto, 2013)

Hasil uji validitas keseluruhan indikator mempunyai sig hitung yang lebih kecil dari 0,05 sehingga dapat dikatakan valid. Sedangkan hasil uji reliabilitas, keseluruhan variabel yaitu strategi diferensiasi, positioning dan persepsi pelanggan Lazada diatas 0,60 sehingga keseluruhan variabel reliabel.

\section{B. Uji Indikator}

\section{a) Convergent Validity}

Convergent Validity diukur dari korelasi antara skor indikator dengan konstruknya. Indikator individu dianggap valid jika memiliki nilai korelasi diatas 0,5, apabila ada indikator yag tidak memenuhi syarat ini, maka harus dibuang. 
Tabel 1

Outer Loading

Variabel Laten

\begin{tabular}{|c|c|c|c|c|c|}
\hline \multirow[b]{2}{*}{$\begin{array}{c}\text { Indikat } \\
\text { or }\end{array}$} & \multicolumn{4}{|c|}{ Variabel Laten } & \multirow[b]{2}{*}{ Status } \\
\hline & $\begin{array}{c}\text { Google Ads } \\
\text { (X1) }\end{array}$ & $\begin{array}{c}\text { Facebook } \\
\text { Ads } \\
\text { (X2) } \\
\end{array}$ & $\begin{array}{c}\text { Brand } \\
\text { Awareness } \\
\text { (Y1) }\end{array}$ & $\begin{array}{c}\text { Keputusan } \\
\text { Membeli } \\
\text { (Y2) }\end{array}$ & \\
\hline GA1 & 0,5943 & & & & Valid \\
\hline GA2 & 0,7182 & & & & Valid \\
\hline GA3 & 0,7805 & & & & Valid \\
\hline GA4 & 0,7808 & & & & Valid \\
\hline GA5 & 0,7729 & & & & Valid \\
\hline GA6 & 0,3578 & & & & Tidak Valid \\
\hline GA7 & 0,4985 & & & & Tidak Valid \\
\hline GA8 & 0,2999 & & & & Tidak Valid \\
\hline FA1 & & 0,8480 & & & Valid \\
\hline FA2 & & 0,9037 & & & Valid \\
\hline FA3 & & 0,8585 & & & Valid \\
\hline FA4 & & 0,5856 & & & Valid \\
\hline FA5 & & 0,8666 & & & Valid \\
\hline FA6 & & 0,7040 & & & Valid \\
\hline FA7 & & 0,7542 & & & Valid \\
\hline FA8 & & 0,2812 & & & Tidak Valid \\
\hline FA9 & & 0,7505 & & & Valid \\
\hline BA1 & & & 0,7897 & & Valid \\
\hline BA2 & & & 0,8323 & & Valid \\
\hline BA3 & & & 0,7979 & & Valid \\
\hline BA4 & & & 0,7869 & & Valid \\
\hline BA5 & & & $-0,0411$ & & Tidak Valid \\
\hline KM1 & & & & 0,8124 & Valid \\
\hline KM2 & & & & 0,8921 & Valid \\
\hline KM3 & & & & 0,7913 & Valid \\
\hline KM4 & & & & 0,8328 & Valid \\
\hline
\end{tabular}

Sumber: Data Primer Diolah, 2020 
Sesuai tabel diatas, terdapat indikator yang tidak valid, karena nilai loading factor masih di bawah 0,5.Oleh karena itu, item yang tidak valid akan disingkirkan dan dilakukan pengujian kembali. Nilai loading factor yang valid adalah $>0,5$.

\section{b) Discriminant Validity}

Hasil pengujian Discriminant Validity adalah sebagai berikut:

Tabel 2

Hasil Uji Discriminant Validity

\begin{tabular}{|c|c|c|c|c|c|}
\hline & Google Ads & Facebook Ads & $\begin{array}{c}\text { Brand } \\
\text { Awareness }\end{array}$ & $\begin{array}{c}\text { Keputusan } \\
\text { Membeli }\end{array}$ & Status \\
\hline GA1 & 0,6412 & 0,2260 & 0,4855 & 0,5139 & Valid \\
\hline GA2 & 0,7181 & 0,4093 & 0,4677 & 0,4892 & Valid \\
\hline GA3 & 0,8130 & 0,3926 & 0,5173 & 0,4852 & Valid \\
\hline GA4 & 0,8135 & 0,4650 & 0,6083 & 0,5637 & Valid \\
\hline GA5 & 0,7676 & 0,6225 & 0,5706 & 0,6313 & Valid \\
\hline FA1 & 0,5737 & 0,8509 & 0,5186 & 0,5792 & Valid \\
\hline FA2 & 0,5575 & 0,9118 & 0,5834 & 0,6602 & Valid \\
\hline FA3 & 0,4548 & 0,8672 & 0,5426 & 0,6251 & Valid \\
\hline FA4 & 0,2938 & 0,5682 & 0,3649 & 0,3311 & Valid \\
\hline FA5 & 0,4358 & 0,8664 & 0,4740 & 0,5705 & Valid \\
\hline FA6 & 0,3263 & 0,7080 & 0,3516 & 0,3872 & Valid \\
\hline FA7 & 0,5165 & 0,7587 & 0,5493 & 0,5259 & Valid \\
\hline FA9 & 0,4878 & 0,7484 & 0,5917 & 0,6544 & Valid \\
\hline BA1 & 0,6412 & 0,5563 & 0,7823 & 0,6783 & Valid \\
\hline BA2 & 0,5117 & 0,4630 & 0,8390 & 0,6259 & Valid \\
\hline BA3 & 0,5509 & 0,5998 & 0,7988 & 0,5788 & Valid \\
\hline BA4 & 0,5603 & 0,4315 & 0,7905 & 0,6638 & Valid \\
\hline KM1 & 0,5370 & 0,5875 & 0,5843 & 0,8122 & Valid \\
\hline KM2 & 0,6007 & 0,6104 & 0,7413 & 0,8935 & Valid \\
\hline KM3 & 0,6076 & 0,6137 & 0,6649 & 0,7889 & Valid \\
\hline KM4 & 0,6452 & 0,5325 & 0,6505 & 0,8339 & Valid \\
\hline
\end{tabular}

Sumber: Data Primer Diolah, 2020. 
Sesuai tabel 2 hasil uji Discriminant Validity semua indikator dinyatakan valid karena berkorelasi terhadap variabel laten lainnya.

Tabel 3

Fornell Lacker Criteria

\begin{tabular}{|c|c|c|c|c|}
\hline & $\begin{array}{c}\text { Brand } \\
\text { Awareness }\end{array}$ & Facebook Ads & $\begin{array}{c}\text { Google } \\
\text { Ads }\end{array}$ & Keputusan Membeli \\
\hline $\begin{array}{l}\text { Brand } \\
\text { Awareness }\end{array}$ & 0,8029 & & & \\
\hline $\begin{array}{l}\text { Facebook } \\
\text { Ads }\end{array}$ & 0,6411 & 0,7920 & & \\
\hline Google Ads & 0,7091 & 0,5833 & 0,7535 & \\
\hline $\begin{array}{l}\text { Keputusan } \\
\text { Membeli }\end{array}$ & 0,7959 & 0,7035 & 0,7185 & 0,8331 \\
\hline
\end{tabular}

Sumber: Data Primer Diolah, 2020

Pada data tabel 3 diketahui bahwa nilai akar AVE konstruk keputusan membeli adalah 0,8331 lebih tinggi daripada korelasi antara konstruk brand awareness, Google Ads dan Facebook Ads. Akar AVE konstruk Google Ads adalah 0,7535 lebih tinggi daripada korelasi antara konstruk brand awareness, keputusan membeli dan Facebook Ads, begitu juga dengan akar AVE konstruk brand awareness adalah 0,8029 lebih tinggi daripada korelasi antara konstruk keputusan membeli, google ads dan Facebook Ads. Sehingga, semua konstruk dalam model yang diestimasi telah memenuhi kriteria discriminant validity.

\section{c) Composite Reliability}

Composite Reliability merupakan ukuran konsistensi internal dari indikator indikator sebuah sebuah variabel bentukan yang menunjukkan derajat dalam variabel yang dibentuk. Untuk mengetahui reliabilitas suatu indikator maka nilai hasil pengujian > 0,7. Hasil pengujian Composite Reliability.

Tabel 4

Hasil Uji Composite Reliability

\begin{tabular}{lcc}
\hline \multicolumn{1}{c}{ Variabel } & Cronbach Alpha & Composite Reliability \\
\hline Google Ads & 0,8070 & 0,8670 \\
\hline Facebook Ads & 0,9119 & 0,9297 \\
\hline Brand Awareness & 0,8162 & 0,8788 \\
\hline $\begin{array}{l}\text { Keputusan } \\
\text { Membeli }\end{array}$ & 0,8521 & 0,9005 \\
\hline
\end{tabular}

Sumber: data Diolah, 2020 
Tabel 4 di atas menunjukkan hasil bahwa nilai Cronbach Alpha dan Composite reliability pada semua konstruk telah mempunyai nilai yang memuaskan yaitu nilai masing-masing diatas 0,70. Berdasarkan nilai tersebut menunjukkan konsistensi dan stabilitas instrumen yang digunakan sangat tinggi, dengan kata lain reliabilitas instrumen telah terpenuhi.

\section{Uji R Square}

Tabel 5

Uji R Square

\begin{tabular}{cc}
\hline & R Square \\
\hline Brand Awareness & 0,5813 \\
\hline Keputusan Pembelian & 0,7235 \\
\hline \multicolumn{2}{c}{ Sumber: data Primer Diolah, 2020 }
\end{tabular}

Data dari data table $5 \mathrm{di}$ atas diketahui bahwa variabel Brand Awareness dipengaruhi oleh Google Ads dan Facebook Ads sebesar 0,5813 atau 58,13\%, dan variabel keputusan membeli dipengaruhi oleh variabel Brand Awareness, Google Ads dan Facebook Ads sebesar 0,7235 atau 72,35\%.

\section{Uji Hipotesis}

Tabel dibawah ini merupakan hasil dari pengujian hipotesis menggunakan SmartPLS.

Tabel 6

Hasil Uji Hipotesis

\begin{tabular}{|c|c|c|c|c|c|c|}
\hline & $\begin{array}{l}\text { Original } \\
\text { Sample }\end{array}$ & $\begin{array}{l}\text { Sample } \\
\text { Mean }\end{array}$ & $\begin{array}{l}\text { Standard } \\
\text { Deviation }\end{array}$ & t Statistics & $\begin{array}{c}P \\
\text { Values }\end{array}$ & Ket. \\
\hline $\begin{array}{l}\text { Google Ads } \rightarrow \\
\text { Brand Awareness }\end{array}$ & 0,5081 & 0,5076 & 0,0692 & 7,3145 & 0,0000 & Terbukti \\
\hline $\begin{array}{l}\text { Facebook Ads } \rightarrow \\
\text { Brand Awareness }\end{array}$ & 0,3447 & 0,3465 & 0,0799 & 4,3145 & 0,0000 & Terbukti \\
\hline $\begin{array}{l}\text { Google Ads } \rightarrow \\
\text { Keputusan } \\
\text { Membeli }\end{array}$ & 0,2385 & 0,2424 & 0,0713 & 3,3463 & 0,0009 & Terbukti \\
\hline $\begin{array}{l}\text { Facebook Ads } \rightarrow \\
\text { Keputusan } \\
\text { Membeli }\end{array}$ & 0,2761 & 0,2787 & 0,0889 & 3,1044 & 0,0020 & Terbukti \\
\hline $\begin{array}{l}\text { Brand Awareness } \\
\rightarrow \text { Keputusan } \\
\text { Membeli }\end{array}$ & 0,4497 & 0,4438 & 0,0947 & 4,749 & 0,0000 & Terbukti \\
\hline
\end{tabular}

Sumber: Data Primer Diolah, 2020 
Arti data tabel 6 diatas adalah sebagai berikut:

a. Hipotesis 1: Google Ads (X1) berpengaruh terhadap Brand Awareness (Y1)

Korelasi variabel Google Ads (X1) dengan Brand Awareness (Y1) menghasilkan nilai koefisien parameter 0,5081 dan $\mathrm{P}$ Value $<0,05$ yaitu 0,0000 . Variabel Google Ads terbukti berpengaruh terhadap Brand Awareness (Y1). Hipotesis 1 diterima

b. Hipotesis 2: Facebook Ads (X2) berpengaruh terhadap Brand Awareness (Y1) korelasi variabel Facebook Ads (X2) dengan Brand Awareness (Y1) menghasilkan nilai koefisien parameter 0,3447 dan P Value < 0,05 yaitu 0,0000. Variabel Facebook Ads terbukti berpengaruh terhadap variabel Brand Awareness (Y1). Hipotesis 2 diterima.

c. Hipotesis 3: Google Ads berpengaruh terhadap keputusan membeli. Korelasi variabel Google Ads (X1) dengan keputusan membeli (Y2) menghasilkan nilai koefisien parameter 0,2385 dan P Value $<0,05$ yaitu 0,0009. Variabel Google $A d s$ terbukti berpengaruh terhadap variabel keputusan membeli (Y2). Hipotesis 3 diterima.

d. Hipotesis 4: Facebook Ads (X2) berpengaruh terhadap keputusan membeli (Y2). Korelasi variabel Facebook Ads (X2) dengan Keputusan Membeli (Y2) menghasilkan nilai koefisien parameter 0,2761 dan P Value < 0,05 yaitu 0,0020. Variabel Facebook Ads terbukti berpengaruh terhadap variabel Keputusan Membeli (Y2). Hipotesis 4 diterima.

e. Hipotesis 5 : Brand Awareness (Y1) berpengaruh terhadap keputusan membeli (Y2). Korelasi variabel Facebook Ads (Y1) dengan Keputusan Membeli (Y2) menghasilkan nilai koefisien parameter 0,4497 dan $\mathrm{P}$ Value $<0,05$ yaitu 0,0000. Variabel Facebook Ads terbukti berpengaruh terhadap variabel Keputusan Membeli (Y2). Hipotesis 5 diterima.

\section{E. Analisis Mediasi}

Analisis mediasi dilakukan dengan cara membandingkan Total Effect (TE) dengan Direct Effect (DE), dengan ketentuan:

Jika TE $>$ DE $\rightarrow$ Maka terjadi efek mediasi dari variabel intervening.

Jika $\mathrm{TE}=$ atau $<\mathrm{DE} \rightarrow$ Maka tidak terjadi efek mediasi dari variabel intervening. 
Analisis Keputusan Membeli Berbasis Brand Awareness Sebagai Impak Google Ads dan Facebook Ads

Tabel 7

Analisis Mediasi

\begin{tabular}{lcccccc}
\hline Variabel & \multicolumn{5}{c}{ Variabel } \\
\cline { 2 - 7 } & \multicolumn{7}{c}{ Direct Effect } & $\begin{array}{c}\text { Indirect } \\
\text { Effect }\end{array}$ & Total Effect & Kesimpulan \\
\cline { 2 - 7 } & $\begin{array}{c}\text { Brand } \\
\text { Awareness (Y1) }\end{array}$ & $\begin{array}{c}\text { Keputusa } \\
\text { n } \\
\text { Membeli } \\
\text { (Y2) }\end{array}$ & $\begin{array}{c}\text { Keputusan } \\
\text { Membeli } \\
\text { (Y2) }\end{array}$ & $\begin{array}{c}\text { Keputusa } \\
\text { n Membeli } \\
\text { (Y2) }\end{array}$ & Sig & \\
\hline \multicolumn{1}{c}{$(1)$} & $(2)$ & $(3)$ & $(4)$ & $(5)=(3)+$ & $(6)$ & $(7)$ \\
\hline $\begin{array}{l}\text { Google } \\
\text { Ads (X1) }\end{array}$ & 0,3081 & 0,2385 & 0,2285 & 0,4670 & 0,0087 & $\begin{array}{c}\text { Intervening } \\
\text { berperan \& } \\
\text { sig. }\end{array}$ \\
\hline $\begin{array}{l}\text { Faceboo } \\
k \text { Ads } \\
\text { (X2) }\end{array}$ & 0,3447 & 0,2761 & 0,1550 & 0,4311 & 0,0000 & $\begin{array}{c}\text { Intervening } \\
\text { berperan \& } \\
\text { sig. }\end{array}$ \\
\hline $\begin{array}{l}\text { Brand } \\
\text { Awarene } \\
\text { ss (Y1) }\end{array}$ & & & & & & \\
\hline
\end{tabular}

Sumber : Data Primer Diolah 2020

Data tabel 7 di atas dapat diartikan sebagai berikut :

a) Pengaruh langsung

1) $\mathrm{X} 1 \rightarrow \mathrm{Y} 1=0,3081 \rightarrow$ Pengaruh langsung Google Ads terhadap Brand Awareness

2) $\mathrm{X} 2 \rightarrow \mathrm{Y} 1=0,3447 \rightarrow$ Pengaruh langsung Facebook Ads terhadap Brand Awareness

3) $\mathrm{X} 1 \rightarrow \mathrm{Y} 2=0,2385 \rightarrow$ Pengaruh langsung Google Ads terhadap keputusan membeli

4) $\mathrm{X} 2 \rightarrow \mathrm{Y} 2=0,2761 \rightarrow$ Pengaruh langsung Facebook Ads terhadap keputusan membeli

5) $\mathrm{Y} 1 \rightarrow \mathrm{Y} 2=0,288 \rightarrow$ Pengaruh langsung Brand Awareness terhadap keputusan membeli

b) Pengaruh Tidak Langsung

Hasil pengujian pengaruh tidak langsung adalah :

1) Variabel Google Ads (X1) berpengaruh terhadap keputusan membeli (Y2).

Variabel Google Ads (X1) berpengaruh terhadap keputusan membeli (Y2) dengan dimediasi oleh variabel Brand Awareness (Y1). Tingkat pengaruh adalah sebesar 22,85\% dan memberikan pengaruh signifikan.

2) Variabel Facebook Ads (X2) berpengaruh terhadap keputusan membeli (Y2). 
Variabel Facebook Ads (X2) berpengaruh terhadap Keputusan Membeli (Y2) dengan dimediasi oleh variabel Brand Awareness (Y1). Tingkat pengaruh adalah sebesar $15,50 \%$ dan menghasilkan pengaruh signifikan.

c) Pengaruh Total (Total Effect)

1. Variabel Google Ads (X1) berpengaruh terhadap keputusan membeli (Y2). Tingkat pengaruh secara langsung dan tidak langsung variabel Google Ads (X1) terhadap keputusan membeli (Y2) adalah 46,70\%. Pengaruh tidak langsung yang dimediasi oleh variabel Brand Awareness (Y1) menghasilkan pengaruh positif dan signifikan terhadap keputusan membeli.

2. Variabel Facebook Ads (X2) berpengaruh terhadap keputusan membeli (Y2). Tingkat pengaruh secara langsung dan tidak langsung variabel Facebook Ads (X2) terhadap keputusan membeli (Y2) adalah 43,11\%. Pengaruh tidak langsung yang dimediasi oleh variabel Brand Awareness (Y1) memberikan pengaruh positif dan signifikan terhadap keputusan membeli.

\section{Kesimpulan}

Berdasarkan penelitian di atas maka dapat disimpulkan bahwa: (1.) Variabel Google Ads (X1) dengan Brand Awarenss (y1) terbukti berpengaruh dan signifikan terhadap Brand Awareness. (2.) variabel Facebook Ads (X2) dengan Brand Awareness (Y1) terbukti berpengaruh dan signifikan terhadap Brand Awareness. (3.) Variabel Google Ads (X1) dengan keputusan membeli (Y2) terbukti berpengaruh dan signifikan terhadap keputusan membeli. (4.) Variabel Facebook Ads (X2) dengan keputusan membeli (Y2) terbukti berpengaruh dan signifikan terhadap keputusan membeli. (5.) variabel Brand Awareness (Y1) dengan keputusan membeli (Y2) terbukti berpengaruh dan signifikan terhadap keputusan membeli. 


\section{BIBLIOGRAFI}

A, Gusti Noorlitaria, Pangestu, Fadillah Ridho, Fitriansyah, Surapati, Untung, \& Mahsyar, Syahriful. (2020). How Does Brand Awareness Affect Purchase Intention In Mediation By Perceived Quality And Brand Loyalty? Journal of Critical Reviews, Vol 7, 202(Issue 2), 1-12.

Arie, Muhammad, Ambolau, Permana, Kusumawati, Andriani, \& Mawardi, Mukhamad Kholid. (2015). The Influence of Brand Awareness and Brand Image on Purchase Decision (Study on Aqua Consumers in Administrative Science Faculty Brawijaya University Class of 2013). Jurnal Administrasi Bisnis (JAB), Vol. 2 No.

Arikunto, Suharsimi. (2013). Prosedur Penelitian Suatu Pendekatan Praktik. Jakarta: Rineka Cipta.

Asnawi, Mizan, Widiarsih, Dwi, Murialti, Neng, Darwin, Ranti, Hidayat, Muhammad, \& Hadi, M. Fikr. (2017). Tingkatkan Omset Dengan Facebook Ads. Jurnal Untuk Mu NegeRI, VOL. 1, NO, 67-71.

Bai, Chunguang, Dallasega, Patrick, Orzes, Guido, \& Sarkis, Joseph. (2020). Industry 4.0 Technologies Assessment: A Sustainability Perspective. International Journal of Production Economics, 229 (2020), 107776.

Bisnis.com. (2020). Survei MarkPlus Inc.: Shopee Kuasai Peta Persaingan Ecommerce. Bisnis.Com. Retrieved from https://ekonomi.bisnis.com/read/20200917 /12/1293028/survei-markplus-inc-shopee-kuasai-peta-persaingan-e-commerce

Cahyani, Khoiriyah Indra, \& Sutrasmawati, Rr. Endang. (2016). Pengaruh Brand Awareness Dan Brand Image Terhadap Keputusan Pembelian. Management Analysis Journal, 5 (4) (201, 281-288.

Chierici, Roberto, Bosco, Barbara Del, Mazzucchelli, Alice, \& Chiacchierini, Claudio. (2019). Enhancing Brand Awareness, Reputation and Loyalty: The Role of Social Media. International Journal of Business and Management, Vol. 14, N(ISSN 18333850 E-ISSN 1833-8119).

Chodick, Gabriel, Teper, Gally Rosenfeld, Levi, Shai, Kopel, Hagit, Kleinbort, Asaf, Khen, Eviatar, Schejter, Eduardo, Shalev, Varda, Stein, Michal, \& Lewis, Nehama. (2020). The impact of a Facebook campaign among mothers on HPV vaccine uptake among their daughters: A randomized field study. Journal of Gynecologic Oncology, xx, 1-6. 
Chris. (2019). 5 Of Most Important Metrics To Track For Google Ads Management. Retrieved from Strategiyeam.com website: https://www.strategybeam.com/blog/5most-important-metrics-for-google-ads-management/

CNBC Indonesia. (2020). Tokopedia Tergeser Ini Dia Jawara e-Commerce Indonesia. Retrieved from CNBCindonesia.com website: https://www.cnbcindonesia.com/tec h/20200824073330-37-181385/tokopedia-tergeser-ini-dia-jawara-e-commerceindonesia

Dehghani, Milad, \& Tumer, Mustafa. (2015). A Research On Effectiveness Of Facebook Advertising On Enhancing Purchase Intention Of Consumers. Journal of Elsevier Computers in Human Behavior, 49(2015), 597-600.

Dreher, Paulette Cutruzzula, Tong, Carmen, Ghiraldi, Eric, \& Friedlander, Justin I. (2018). Use of Google Trends to Track Online Behavior and Interest in Kidney Stone Surgery. Journal of Urology.

E.B, Gita Aprinta. (2016). Pemanfaatan Facebook Ads Untuk meningkatkan Brand Awareness pada Produk Lokal. The Messenger, Volume VII, 68-72.

Farah, Maya F., \& Ramadan, Zahy B. (2017). The Pokémonisation of the first moment of truth. International Journal of Web Based Communities (IJWBC), Vol. 13, N, 262-277.

Franedya, Roy. (2019). Survei: Pengguna Internet di RI Tembus 171,17 Juta Jiwa. Retrieved March 30, 2020, from CNBCindonesia.com website: https://www.cnbcin donesia.com/tech/20190516191935-37-73041/survei-pengguna-internet-di-ritembus-17117-juta-jiwa

Gendro Wiyono. (2011). Merancang Penelitian Bisnis. Yogyakarta: UPP STIM YKPN.

Gityandraputra, Dimas. (2020). Memahami Google Ads dan Manfaatnya untuk Mendukung Pemasaran. Retrieved April 2, 2020, from Getcraft.com website: https://academy.getcraft.com/id/blog/memahami-google-ads-dan-manfaatnya

Gunawardane, Nisal Rochana. (2015). Impact of Brand Equity towards Purchasing Desition: A Situation on Mobile Telecommunication Services of Sri Lanka. Journal of Marketing Management, Vol. 3, No, 100-117.

Gupta, Shaphali, Leszkiewicz, Agata, Kumar, V., Bijmolt, Tammo, \& Potapov, Dmitriy. (2020). Digital Analytics: Modeling for Insights and New Methods. 
Journal of Interactive Marketing, xx (2020), xxx.

Huang, Shan, Aral, Sinan, Hu, Yu Jeffrey, \& Brynjolfsson, Erik. (2020). Social Advertising Effectiveness Across Products: A Large-Scale Field Experiment. Journal of Marketing Science, Oktober(Advance), 1-24.

Ibarra, Dorleta, Ganzarain, Jaione, \& Igartua, Juan Ignacio. (2018). Business model innovation through Industry 4.0: A review. Procedia Manufacturing, 22, 4-10.

Ibarra Zuluaga, Dorleta, Ganzarain Epelde, Jaione, \& Igartua López, Juan Ignacio. (2018). Business model innovation through industry 4.0: a review. Procedia Manufacturing, Vol. 22. 2, Pp. 4-10.

iPrice. (2018). Kilas Balik Ecommerce Platform di Indonesia Tahun 2018. Retrieved from iprice.co.id website: https://iprice.co.id/trend/insights/kilas-balik-ecommerce-di-indonesia-tahun-2018/

Kemp, S. (2019). Indonesia Digital 2019.

Kilei, Peary, (PhD), Dr. Mike Iravo, \& (PhD), Dr. Jane Omwenga. (2016). The Impact Of Brand Awareness On Market Brand Performance Of Service Brands: Contextual Consideration of Kenya's Banking Industry. European Journal of Business and Management, Vol.8, No.(ISSN 2222-2839 (Online)), 92-103.

Kotler, Phillip, \& Kevin, L. Keller. (2016). Marketing Management.Edition 16 (16th ed.). New Jersey, US: Pearson.

Kusuma, Ngurah Bagus Angga Primanda, \& Miartana, Putu. (2018). Brand Awareness, Brand Loyalty, Perceived Quality, Brand Association Brand Preference dan Purchase Intention. Jurnal Manajemen Dan Bisnis, Volume 15,

Leanne. (2020). The Most Important Facebook Ad Metrics You Should Be Monitoring \& Optimizing. Retrieved October 22, 2020, from Lyfemarketing.com website: https://www.lyfemarketing.com/blog/facebook-ad-metrics/

Lee, Ju Yeon, (Er), Eric Fang, Kim, Jisu J., Li, Xiaoling, \& Palmatier, Robert W. (2018). The Effect of Online Shopping Platform Strategies on Search, Display, and Membership Revenues. Journal of Retailing, xxx (xxx, 1-18.

Liputan6.com. (2019). Daftar E-Commerce dengan Transaksi Tertinggi di RI, Siapa Saja? Retrieved from https:/www.liputan6.com/bisnis/read/4048211/daftar-ecommerce-dengan-transaksi-tertinggi-di-ri-siapa-saja 
Bertinus Sijabat

M.S, Jayaweera, F, Azam. S. M., \& A, Khatibi. (2018). The impact of Performance Expectancy \& Effort Expectancy on the usage of Social Media with Special Reference to Sri Lankan multispecialty Tertiary care Hospitals. International Journal of Advances in Scientific Research and Engineering, Volume 4,(Issue 11 November-2018), 83-87.

Martin, Kelly D., \& Murphy, Patrick E. (2017). The role of data privacy in marketing. Journal of the Academy of Marketing Science, volume 45, pages135-155.

Medcom.id. (2017). Lazada dan Tokopedia Jadi Raja E-Commerce Indonesia 2017. Retrieved from Medcom.id website: https://www.medcom.id/teknologi/newsteknologi/8KyvZP2N-lazada-dan-tokopedia-jadi-raja-e-commerce-indonesia-2017

Medina, Carlos Alberto Guerrero, Martinez-Fiestas, Myriam, Viedma-delJesús, María I., \& Aranda, Luis Alberto Casado. (2020). The processing of price during purchase decision making: Are there neural differences among prosocial and nonprosocial consumers? Journal of Cleaner Production, Juni 2020, 1-29.

Mulyono, Herry. (2016). Brand Awareness And Brand Image Of Decision Making On University. Jurnal Manajemen Dan Kewirausahaan, VOL. 18, N, 163-173.

Pamungkas, Danang, \& Fanani, Dahlan. (2018). Pengaruh Iklan Google Adwords Terhadap Perilaku Share Konsumen. Jurnal Administrasi Bisnis (JAB), Vol. 62 No, 124-130.

Pancaningrum, Erminati, \& Rahayu, Wahyu Ari. (2017). The Effectiveness of Facebook as an Advertising Strategic Method Using EPIC: A Case Study of Mie Jupe Jombang. Chinese Business Review, July 2017, 309-315.

Paruthi, Mandakini, \& Kaur, Harsandaldeep. (2017). Scale Development and Validation for Measuring Online Engagement. Journal of Internet Commerce, 16(2), 127-147.

Pranata, I. Wayan Dicky Reza, \& Pramudana, Km. Agus Satria. (2018). Peran Kesadaran Merek (Brand Awareness) Dalam Memediasi Hubungan Iklan Oppo Dengan Niat Beli Konsumen. E-Jurnal Manajemen Unud, Vol. 7, No.

Putra, M. K. W. (2019). Manfaat Google AdWords Sebagai Media Periklanan Produk Berbasis Daring Terhadap Masyarakat Generasi Z. (112), 1-7.

Raharjo, Steven Tirto, \& Prof. Dr. Hatane Semuel S.E., M. S. (2018). Pengaruh Social Media Marketing Terhadap Purchase Intention melalui Brand Awareness Sebagai 
Variabel Mediasi pada Lazada. 1-6.

Ramadan, Zahy B., Farah, Maya F., \& Kassab, Danielle. (2019). Amazon's Approach To Consumers' Usage Of The Dash Button And Its Effect On Purchase Decision Involvement In The U.S. Market. Journal of Retailing and Consumer Services, 47 (2019), 133-139.

Ramadayanti, Firda. (2019). Peran Brand Awereness Terhadap Keputusan Pembelian Produk. Jurnal Studi Manajemen Dan Bisnis, Vol. 6 (2), hlm. 78-83.

Rybaczewska, Maria, Sparks, Leigh, \& Sułkowski, Łukasz. (2020). Consumers' Purchase Decisions And Employer Image. Journal of Retailing and Consumer Services, 55 (2020), 102123.

Schiffman, Leon G., \& Wisenblit, Joseph L. (2015). Consumer Behavior (11th ed Gl). Pearson Education Inc.

Shahid, Zarlish, Hussain, Tehmeena, \& AZafar, Dr. Fareeh. (2017). The Impact of Brand Awareness on The consumers' Purchase Intention. Journal of Marketing and Consumer Research, Vol.33, 20(ISSN 2422-8451 An International Peer-reviewed Journal).

Sung, Yoon Hi, Kim, Dong Hoo, Choi, Dongwon, \& Lee, So Young. (2020). Facebook Ads Not Working In The Same Way: The Effect Of Cultural Orientation And Message Construals On Consumer Response To Social Media Ads. Journal of Telematics and Informatics, 52 (2020), 101427.

Sürücü, Özlem, Öztürk, Yüksel, Okumus, Fevzi, \& Bilgihan, Anil. (2019). Brand Awareness, Image, Physical Quality And Employee Behavior As Building Blocks Of Customer-Based Brand Equity: Consequences In The Hotel Context. Journal of Hospitality and Tourism Management, 40 (2019), 114-124.

Swamy, Vighneswara, Dharani, M., \& Takeda, Fumiko. (2019). Investor Attention And Google Search Volume Index: Evidence From An Emerging Market Using Quantile Regression Analysis. Research in International Business and Finance, 50 (2019), 1-17.

Tata, Sai Vijay, Prashar, Sanjeev, \& Gupta, Sumeet. (2019). An Examination Of The Role Of Review Valence And Review Source In Varying Consumption Contexts On Purchase Decision. Journal of Retailing and Consumer Services, Januari, 1-10.

Techfor. (2019). Facebook Ads: Pengertian dari Facebook Marketing. Retrieved 
October 23, 2020, from Techfor.id website: https://www.techfor.id/facebook-adspengertian-dari-facebook-marketing/

Tikno. (2017). Measuring performance of facebook advertising based on media used: a case study on online shops in indonesia. Procedia Computer Science, 111 (2017), $105-112$.

Timpal, Nicky, S.L.H.V.J, Lapian, \& Rate, Paulina Van. (2016). The Influence Of Brand Awareness And Brand Attitude On Purchase Decision Of Nokia Handphone (Case Study At High School Students In Manado City). Jurnal Berkala Ilmiah Efisiensi, Volume 16.

Upadhyay, Ushma D., Jovel, Iris J., McCuaig, Kevin D., \& Cartwright, Alice F. (2019). in the United States (US) who were considering abortion at the point of searching for an abortion clinic. Study design: We conducted the Google Ads Abortion Access Study, a national cohort study using a novel recruitment method recruiting people searchi. Journal of Contraception: X, X 2 (2020), 100017.

Ursu, Raluca M. (2018). The Power of Rankings: Quantifying the Effect of Rankings on Online Consumer Search and Purchase Decisions. Marketing Science, (Articles in Advance, ), 1-23.

Vries, Lisette de, Gensler, Sonja, \& Leeflang, Peter S. H. (2017). Effects of Traditional Advertising and Social Messages on Brand-Building Metrics and Customer Acquisition. American Marketing Association Journal of Marketing, September, $1-54$.

Wasil, Mohammad. (2017). Pengaruh brand awareness brand association dan percieved quality. Forum Ekonomi, Volume 19, 137-147.

We Are Social, \& Hootsuite. (2020). Digital 2020 Indonesia. Retrieved November 10, 2020, from datareportal.com website: datareportal.com

Widiartanto, Y. H. (2016). Pengguna Internet di Indonesia Capai 132 Juta. Kompas.Com. Https://Tekno.Kompas.Com/Read/2016/10/24/15064727/2016.Peng guna.Internet.Di.Indonesia.Capai.132.Juta.

Wiese, Melanie, Martínez-Climent, Carla, \& Botella-Carrubi, Dolores. (2020). A Framework For Facebook Advertising Effectiveness: A Behavioral Perspective. Journal of Business Research, 109 (2020), 76-87.

Za, Saida Zainurossalamia, \& Tricahyadinata, Irsan. (2017). An Analysis on the Use of 
Analisis Keputusan Membeli Berbasis Brand Awareness Sebagai Impak Google Ads dan Facebook Ads

Google AdWords to Increase E-Commerce Sales. International Journal of Social Sciences and Management, Vol. 4(Issue-1: 60-67).

Zhang, Mei. (2020). Decision-Making Processes In Academic Libraries: How Did Academic Librarians Purchase E-Book Products? The Journal of Academic Librarianship, 46 (2020), 102252.

Zia, Mohammad, \& Rao, Ram C. (2019). Search Advertising: Budget Allocation Across Search Engines. Journal of Marketing Science, Advance Ok, 1-15. 